\title{
Differential and empirical model for describing psycholinguistic meanings
}

\author{
Mairbeck Makhaev ${ }^{1,2,3^{*}}$, Khouzu Mamalova ${ }^{4}$, and Arby Vagapov ${ }^{5}$ \\ ${ }^{1} \mathrm{Kh}$. Ibragimov Complex Institute Research of the Russian Academy of Sciences, laboratory of \\ philology and cultural studies, 364051 21a Staropromyslovskoe shosse, Visaitov, Russian Federation \\ ${ }^{2}$ Daghestan Federal Research Centre of the Russian Academy of Sciences, Dagestan psycholinguistic \\ society, 367032, 45 Gadjieva street, Makhachkala Russian Federation \\ ${ }^{3}$ M.A. Shavkhalov named Ingush Scientific Research University, laboratory of psycholinguistic \\ research, 386 200, 24 Engels street, Sunza, Russian Federation \\ ${ }^{4}$ Chechen State University, 364907, department of Chechen philology, 32 Sheripov street, Grozny, \\ Chechen Republic, Russian Federation \\ ${ }^{5}$ Academy of Sciences of the Chechen Republic, 364024, 13 M.Isinbaeva, Grozny, Chechen \\ Republic, Russian Federation
}

\begin{abstract}
The paper is devoted to the problem of semantics of proper names. Nowadays, in linguistics, there are different points of view on the nature of the semantics of proper names. This paper states the discovery of a new kind of meaning of proper names - psycholinguistic. This concept is based on the use of experimental methods for studying the meanings of words, which involves an appeal to the consciousness of native speakers. Psycholinguistic experiments were carried out by us in Voronezh. Subjects - 330 students. The method of free and directed associative experiment was used. Various toponyms ("Moscow", "St. Petersburg", "Volgograd"), including "Voronezh", were used as a stimulus material. According to the results of experiments on the stimulus "Voronezh", a total of 1,055 verbal associative reactions were obtained. Then the semantic interpretation of associative reactions was carried out, which consists in understanding the reactions as linguistic representations of certain signs of the denotation semantic components. As a result, the psycholinguistic meaning of the toponym "Voronezh" was formulated, which is very different from its meaning in toponymic dictionaries. We call this new kind of meaning psycholinguistic.
\end{abstract}

\section{Introduction}

Proper names actively function in various types of discourse and play an important role in communication between people [1].

Studying the nature of proper names, one cannot ignore the problem that affects their meaning, lexical content.

Numerous works are devoted to the problem of semantics of proper names [2-6]. Attempts have been made to determine the essence of a proper name based on its functions

* Corresponding author: makhaev-87tomsk@mail.ru 
and meaning. However, a different understanding of the problem leads to a different understanding of the essence of the phenomenon.

Nowadays, there is no definite answer to the question of whether names have their own meaning.

At least three positions are distinguished with respect to the semantics of proper names.

The first group of concepts can be called a group of "negativist» (anti-semantic) concepts. They assert that proper names are not associated with the expression of concepts (significations) [7].

The second group consists of "semantic» concepts. Their supporters believe that proper names acquire meaning at the moment of use in speech, i.e. in speech contexts [8].

In the concepts of the third group, it is stated that proper names have a meaning both in language and in speech. But unlike the semantics of appellatives, the semantics of proper names reflects the specific, unique, singular meaning [7]

The results of our psycholinguistic experiments $[9,10]$ show that proper nouns have a very specific semantics, have a rich semantic volume. It is the experiment that gives access to the volumetric and deep semantics of the onym.

Lexicographers a priori proceed from the fact that the proper name described in dictionaries exists in the language precisely in the semantic volume that is presented in the dictionary definition, and in the same volume this lexeme is understood and used in speech.

However, psycholinguistic experiments make it possible to identify numerous semes in the meanings of words that are not recorded in the definitions of explanatory dictionaries and are not identified by the results of the analysis of contexts of use, but are relevant for native speakers.

An experimental description of the semantics of toponyms makes it possible to present their content as a certain psychological reality, to identify such semantic components that are not fixed by other, traditional methods and techniques of semantic analysis.

The results of the experiments made it possible to reveal a new kind of meaning of proper names - the psycholinguistic meaning, which exists in the language along with the traditional dictionary meaning [11-13].

Psycholinguistic meaning is a meaning that is actually represented in the minds of native speakers (as opposed to the dictionary meaning that is presented in dictionaries).

We have developed a differential and empirical model of description and lexicographic fixation of the semantics of proper names, which allows identifying psycholinguistic meanings.

Our concept was created within the framework of the anthropocentric paradigm, which testifies to a methodological shift in modern linguistics: from the attitude to explore the language " in oneself and for oneself» to the attitude to study the language in close connection with a person.

The psycholinguistic meaning makes it possible to contribute to the solution of one of the most important methodological problems of lexicography - methods of complex interpretation of the semantics of lexical units, taking into account the mental factor, i.e. an analysis of the language in its close relationship with the thinking of an individual, experience of his spiritual and practical activities

Psycholinguistic interpretations of lexemes reflect real meanings of words in the linguistic consciousness of native speakers, make it possible to identify new semantic components that have not been recorded in explanatory dictionaries, to reveal the degree of their relevance for native speakers, and to identify features of the verbal communicative behavior of the linguocultural community 


\section{Materials and methods}

The general algorithm for identifying and analyzing psycholinguistic meanings consists of 4 main stages, which include: 1) conducting a psycholinguistic experiment with the words studied as stimuli; 2) processing of the obtained associative reactions and construction of associative fields of words; 3) semantic interpretation of associative fields and identification of semantic components (seme); 4) sememic attribution of semes and identification of psycholinguistic meanings; 5) comparative analysis of psycholinguistic and dictionary meanings.

Psycholinguistic experiments were carried out from December 2017 to January 2019 in Voronezh. The subjects (330 people) were students of Voronezh universities of both sexes, different courses and specialties in the age range from 16 to 30 years old.

A list of 10 toponyms was used as a stimulus material (Vladikavkaz, Volgograd, Voronezh, Grozny, Dagestan, Derbent, Ingushetia, Moscow, St. Petersburg, Chechnya).

Experiments were carried out in the lecture halls of local universities in writing according to the following scheme: the subjects received experimental A4 forms with a list of 10 toponym stimuli and instructions: "Answer any word that comes to mind when you hear this word" / "X - what is it famous for?"," Where is X?"

The experiments used: to identify free associative reactions - the method of free nonchain associative experiment (the instruction "Answer with any word that comes to mind when you hear this word") and to identify directed associative reactions - the method of directed chain associative experiment ("X - what is it famous for?"," Where is X?").

Before starting the experiment, the experimenter gave the subjects explanations on how to fill in the forms correctly. The time for filling them was not limited (filling was completed on average within 15 minutes).

\section{Results and discussion}

The data was processed manually. A total of 1,055 verbal associative responses were received with 66 refusals.

After processing the obtained associative reactions, three associative fields of toponyms were built: the first - from free reactions, the second and third - from directed reactions.

For a sample, we will give brief information about the associative fields of the toponym "Voronezh". The dictionary entries contain reactions with a frequency of at least 5.

Associative field with free associative reactions:

Voronezh - 330: home 30; VSU 19; Homeland 14; city of courage 13; the capital of the Black Earth Region 12; City of Military Glory; you will not catch up; native city; study - 9; courage 8; fleet; black soil - 7; kitten from Lizyukov Street; Peter the Great; river; university; Black earth - 6 ; city $5 \ldots$

Refusals - 5

Associative fields with directed associative reactions:

Voronezh. What is it famous for? - 330: city of military glory 29; the capital of the Black Earth Region 15; VSU 14; a kitten from Lizyukov Street 11; Hero City 10; cradle of the Russian fleet 8; shipbuilding 7; fleet 5 ...

Refusals -30

Unprocessed reactions - 3 (illegible handwriting)

Voronezh. Where is it? - 330: Russia 27; Voronezh region 28; central Russia 22; central part of Russia 17; Black earth 15; Central Federal District 15; the capital of the Black Earth Region 8; center of Chernozem region 8; central Chernozem region; center of Russia - 6; in the heart; West of Russia; here; in the European part of Russia - 5;

Refusals -31 
Entries have the following structure: 1) the headword (stimulus lexeme in bold); 2) the number of subjects in the experiments (the number after the headword); 3) lexemesreactions with an indication of their frequency (numbers after lexemes-reactions); refusals (the number of refusals corresponds to the number of empty spaces in the experimental forms); unprocessed reactions (some reactions were not processed due to various reasons: illegible handwriting, incorrect performance of the task, etc.).

Then the semantic interpretation of the associative fields was carried out, and the semantic components were identified.

The semantic interpretation means that associative reactions are interpreted as linguistic representations of certain signs of a denotation - seme. For example, the reactions "VSU" (Voronezh State University) and "university" are defined as the representation of the seme "there are higher educational institutions", and the reactions "central Russia", "central part of Russia", "center of Russia" are defined as the seme "located in the central part of the Russian Federation".

However, not all associative responses were interpreted, since in some cases a meaningful connection between stimulus and response was not established. For example, "here" 5, "below Moscow" 2, "Voronezh" 2, "we are" 2, "Azerbaijan, time" 1, "village" 1, "here" 1, "green" 1, "land" 1, "contrast" 1, etc. In total - 63 not interpreted reactions (table 1).

Table 1. The ratio of the number of subjects, reactions, refusals and not interpreted reactions.

\begin{tabular}{|c|c|c|c|}
\hline $\begin{array}{c}\text { Number of } \\
\text { subjects }\end{array}$ & $\begin{array}{c}\text { The number of } \\
\text { reactions to the } \\
\text { stimulus } \\
\text { "Voronezh" }\end{array}$ & $\begin{array}{c}\text { Number of } \\
\text { refusals }\end{array}$ & $\begin{array}{c}\text { Number of not } \\
\text { interpreted } \\
\text { reactions }\end{array}$ \\
\hline 330 people & 1055 reactions & 66 & 63 \\
\hline
\end{tabular}

As a result of semantic interpretation, 147 semantic components were identified. For each seme, verve indices are calculated, which show the place occupied by the seme in the mind of a native speaker.

The verve index is calculated by the formula (1)

Verve index $=n / N$

(1)

$n$ - the number of subjects who actualized seme in the experiments; $N$-total number of subjects.

For example, the seme "city" has a verve index of $0.01(5 / 330)$.

Semes are the most verve (with a high verve index) and the least verve (with a low verve index).

In accordance with the indicator of the verve index, the semes are distributed according to the zones of value (this is called the field belonging of the seme)

Table 2. Field belonging of seme in the structure of meaning.

\begin{tabular}{|c|c|c|c|}
\hline Core & $\begin{array}{l}\text { Near } \\
\text { periphery }\end{array}$ & $\begin{array}{l}\text { Far } \\
\text { periphery }\end{array}$ & $\begin{array}{c}\text { Extreme } \\
\text { periphery }\end{array}$ \\
\hline $\begin{array}{lr}\text { verve } & \text { index } \\
0.12 & \text { and } \\
\text { above } & \end{array}$ & $\begin{array}{l}\text { verve index } \\
0.11-0.04\end{array}$ & $\begin{array}{l}\text { verve } \\
\text { index } \\
0.03-0.02\end{array}$ & $\begin{array}{lr}\text { verve index } \\
0.01 \text { and } \\
\text { lower }\end{array}$ \\
\hline
\end{tabular}

Out of 147 semantic components, only 5 are included in the core of the field, the rest occupy peripheral positions. 
As a result of the semantic interpretation of the reactions and the calculation of the verve indices of the identified semantic components, the psycholinguistic meaning of the toponym "Voronezh" was formulated.

The psycholinguistic meaning of the toponym can be formulated by indicating all 147 identified semes. However, this would result in a very long description. In this paper, we will present a brief description of the psycholinguistic meaning of the toponym "Voronezh", based on core semes. We emphasize that it is mandatory to include an integral seme (in this case, "city") in an entry, regardless of its verve index. In our case, the seme "city" has a low verve index (0.01), but at the same time it will be included in the psycholinguistic meaning.

Voronezh is a city (0.01), part of the Central Black Earth Economic Region (0.30), the place of foundation of the Russian Navy (0.26), a city of military glory $(0.17)$, the scene of the cartoon "Kitten from Lizyukov Street" $(0.13)$, my place of residence $(0.12)$.

The structure of an entry with a description of the psycholinguistic meaning: the left side of the definition is a headword highlighted in bold; after the headword, the semantic components are given, ordered according to the principle "first integral, then - differential semes"; all semes are given with indication of their verve indices (the number after the seme). Semes are given in the paper in descending order of verve indices.

Further, in order to carry out a comparative analysis of the psycholinguistic and dictionary meanings, we will give several dictionary meanings of the toponym "Voronezh" presented in toponymic dictionaries.

"Voronezh, city, regional center. Founded in 1586 as a fortress on the Voronezh river, for which it was named. And the river was named after another, the ancient city of Voronezh, destroyed during the Mongol-Tatar invasion. The name of ancient Voronezh was transferred to the Don region from the Chernigov principality, where it appeared in the 9th century as a possessive adjective from the personal name Voroneg" (14 Pospelov, p.92).

Let's pay attention that in the dictionary and psycholinguistic definitions, only one seme coincided - "city", while this seme occupies a peripheral position in the psycholinguistic meaning, i.e. has a low degree of relevance for native speakers in Voronezh. In the dictionary definitions, there are many historical semes associated with the founding of the city, as well as the origin of the word "Voronezh". For Voronezh native speakers, other historical semes are relevant - for example, the seme "the place where the Russian navy was founded", which has a fairly high verve index.

The fact that the city is part of the Central Black Earth Economic Region, the status of a city of military glory, as well as the fact that the city has become the scene of the cartoon "Kitten from Lizyukov Street" are also relevant for Voronezh native speakers. It is also important for Voronezh residents that the city is their place of living. Therefore, the corresponding semes are at the core of the psycholinguistic meaning of the toponym "Voronezh".

Dictionary definitions are absolutely necessary, and we do not deny their importance. However, we believe that dictionary definitions reflect the set of semantic components that the lexicographer determines subjectively on the basis of intuition. The differential and empirical model makes it possible to introduce elements of precision into the process of lexicography: the meanings reflect those semes that are really relevant for a particular linguistic community. In this case, the degree of relevance is calculated.

\section{Conclusions}

Thus, the analysis of the semantics of the toponym "Voronezh" using experimental methods revealed the presence of numerous semantic components that have a certain degree of relevance for the linguistic community. The psycholinguistic meaning of the 
toponym was formulated, reflecting the real functioning of its semantics in the minds of Voronezh native speakers.

Comparison of psycholinguistic and dictionary meanings showed that the dictionary definitions included a lot of semes that are irrelevant for native speakers.

Thus, the differential and empirical model makes it possible to identify semes of toponyms that are relevant and irrelevant for a modern native speaker (the degree of relevance of semes is revealed through the calculation of their verve index, as well as comparison with semes indicated in dictionary definitions in linguistic dictionaries), to find new semes that are not recorded in linguistic dictionaries [15], to identify, along with psychologically relevant conventional meanings of toponyms, occasional meanings formulated on the basis of the semantic interpretation of individual associative reactions (far and extreme periphery of meaning), etc.

The differential and empirical model also can be applied to the analysis of the semantics of metaphors. We may:

- identification of existing semes of metaphors (nuclear and peripheral).

- identification of new semes not recorded in the explanatory dictionaries and corpora of national languages.

- fixation of outdated (irrelevant for linguistic consciousness) semantic components of metaphors (based on the results of a comparative analysis with the lexicographic meanings of metaphors recorded in the explanatory dictionaries).

- identification of occasional meanings based on the semantic interpretation of individual associative reactions (far and extreme peripheries). Occasional meanings will make it possible to determine the semantic potential of a metaphor, the possible direction of semantic development. In the dictionary entry, they will be marked with \#

- identification of the ethno-cultural specifics of metaphors whose importance is due to the fact that the figurative structure of language is a nationally and culturally determined system of images fixed in the usus, metaphorically realized in the semantics of lexical and phraseological units and forming a linguistic picture the world.

- identification of gender, social and age semantics will allow for qualitative differentiation of semes by groups.

- identification of the temporal semantics of metaphors, which entails repeated experiments, to obtain data on the semantics of metaphors at time $t$ and fix the dynamics of semantic processes (transformation of the content and semantic structure of metaphors at different times).

- identification of the degree of mastery of the semantics of metaphors by linguistic consciousness

This approach developed by the Voronezh scientific theoretical and linguistic school on the basis of the Dagestan psycholinguistic circle at the Dagestan Federal Research Center of the Russian Academy of Sciences and the Laboratory of Philology and Cultural Studies Integrated Research Institute of the Russian Academy of Sciences and M.A. Shavkhalov named Ingush Scientific Research University, laboratory of psycholinguistic (under the guidance of M.R. Makhaev).

We invite our colleagues to cooperate.

\section{References}

1. T.O'Rourke, R. Diego, Neuroscience \& Biobehavioral Reviews, 108, 308-321 (2020), https://doi.org/10.1016/j.neubiorev.2019.11.005

2. K.D. Mueller, R.L. Koscik, L. Du, D. Bruno, E.M. Jonaitis, A.Z. Koscik, B.T.

Christian, T.J. Betthauser, N.A. Chin, B.P. Hermann, S.C. Johnson, Cortex, 131, $137-$ 150 (2020) https://doi.org/10.1016/j.cortex.2020.07.008 
3. A. Jaber, O. Omari, Language Sciences 69, 113-124 (2018) https://doi.org/10.1016/j.langsci.2018.07.002

4. A. Aksholakova, Procedia - Social and Behavioral Sciences, 112, 465-471 (2014) https://doi.org/10.1016/j.sbspro.2014.01.1190

5. Th. Busigny, X. Boissezon, M. Puel, J.-L. Nespoulous, E.J. Barbeau, Cortex, 65, 1-18 (2015) https://doi.org/10.1016/j.cortex.2014.12.008

6. A.A. Kim-Maloney, A. Kim, A. Tereschenko, Procedia - Social and Behavioral Sciences, 154, 92-98 (2014) https://doi.org/10.1016/j.sbspro.2014.10.118

7. A.N. Derevyago, A Proper Name in a Literary Text (Vitebsk: UO "VSU named after P. M. Masherov", 2008)

8. A.V. Superanskaya, General Theory of The Proper Name (Moscow: Book House "LIBROCOM", 2012)

9. M.R. Makhaev, I.A. Sternin, D.K. Ibragimov, The European Proceedings of Social \& Behavioural Sciences, LVIII, 1007-1014 (2019) DOI: 10.15405/epsbs.2019.03.02.116

10. M.R. Makhaev, S.Kh.S.E. Ireziev, T.K. Abdulazimova, Kh.R. Selmurzaeva, K.B. Navrazova, The European Proceedings of Social \& Behavioural Sciences, 92, 3113 3120 (2020) DOI: 10.15405/epsbs.2020.10.05.413

11. I.A. Sternin, A.V. Rudakova, Dictionary Definitions and Semantic Analysis (Voronezh: "Istoki", 2017)

12. I.A. Sternin, A.V. Rudakova, Psycholinguistic Meaning of the Word and its Description. (Chisinau: Lambert Academic Publishing, 2011)

13. M.R. Makhaev, N.A. Polekhin, I.A. Sternin, Bulletin of the Social-Pedagogical Institute, 1, 44-51 (2018)

14. E.M. Pospelov, Toponymic Dictionary: About 1500 Units (Moscow, Astrel: AST, 2005)

15. I.A. Sternin, Methods for Describing the Semantics of the Word (Yaroslavl, Istoki, 2013) 